\title{
Bone Loss or a Case of Mistaken Gender?
}

\section{Joao Lindolfo C Borges ${ }^{1,2 *}$, Haddad LP2 and Lewiecki EM ${ }^{3}$}

${ }^{1}$ Universidade Católica de Brasília, Brazil

${ }^{2}$ Centro de Pesquisa Clínica do Brasil, Brazil

${ }^{3}$ New Mexico Clinical Research \& Osteoporosis Center, USA

${ }^{*}$ Corresponding author: Joao Lindolfo C Borges, Universidade Católica de Brasília, Brazil, Tel: 5561-81371442; Fax: 561-33641117; E-mail: jlborges@metabolismo.com.br

Received date: May 25, 2016; Accepted date: June 28, 2016; Published date: June 30, 2016

Citation: Borges JLC, Haddad LP, Lewiecki EM (2016) Bone Loss or a Case of Mistaken Gender? J Clin Exp Orthop 2: 3. doi: 10.4172/2471-8416.100020

Copyright: @ 2016 Borges JLC, et al. This is an open-access article distributed under the terms of the Creative Commons Attribution License, which permits unrestricted use, distribution, and reproduction in any medium, provided the original author and source are credited.

\section{Abstract}

Osteoporosis can occur in men and women of any age or ethnicity. Osteoporotic fractures are associated with increased mortality, even in younger patients. Hip fractures and vertebral fractures are public health concerns due to long-term disability and high Cost. The lifetime risk of an osteoporotic fracture in men over the age of 50 years is about 1 in 4, with the chances of a new fracture higher than the lifetime risk of developing prostate cancer. The mortality associated with hip fractures is higher in men that in women. By 2025, the estimated number of hip fractures occurring worldwide in men will be close to that seen in women in 1990. Dualenergy X-ray absorptiometry (DXA) is the "gold-standard" technology for the diagnosis of osteoporosis and monitoring the skeletal effects of treatment. However, DXA results can sometimes be misleading due to errors in patient positioning, incorrect analysis, invalid data, or poor interpretation. This case presentation illustrates an easily avoidable testing error that could lead to inappropriate treatment decisions, highlighting the importance of quality DXA testing and reporting.

Keywords: DXA; Scan interpretation; DXA analysis; Osteoporosis; Men; DXA guidelines

\section{Introduction}

Dual-energy X-ray absorptiometry (DXA) is a non-invasive, widely available, modestly priced technology for measuring bone mineral density (BMD). It is conveniently performed with a rapid acquisition time and a low dose of ionizing radiation. DXA is used to diagnose, monitor osteoporosis, and assess fracture risk, and monitor changes in BMD over time [1-5].
Despite the ease of performing a DXA study, its clinical utility requires close attention to detail by a well-trained technologist and interpretation by a knowledgeable physician according to well-established standards [6]. Each DXA system uses reference population databases to calculate T-scores and Zscores, representing the standard deviation difference between the patient's BMD and a young-adult reference population and an age-matched population, respectively. Since there are many available reference databases, care must be taken to select those that are most appropriate according to applicable standards. The case presented here illustrates the clinical implications of inconsistent selection of a young-adult reference database for calculating T-scores in men.

\section{Case Report}

A 79-year-old Caucasian male presents for a screening DXA scan, as recommend by the US National Osteoporosis Foundation and the International Society for Clinical Densitometry. He is $170 \mathrm{~cm}$ (67 inches) tall and weighs $80 \mathrm{~kg}$ (176 pounds) with $\mathrm{BMI}=26.2$. This showed a T-score of -2.4 at the lumbar spine (Figure 1). There was no spine fracture on the spine radiographic evaluation. The patient was treated with denosumab, $60 \mathrm{mg}$ subcutaneously, every six months plus calcium and vitamin D. His treatment compliance was excellent. He was not on any treatment known to be harmful or beneficial to bone metabolism. A second DXA scan performed two years later, showed a lumbar spine T-score of -2.6 (Figure 2), slightly worse than the baseline scan, although the BMD was numerically higher. What is the explanation for the T-score and BMD apparently changing in opposite directions? Is this patient a suboptimal responder to treatment? To answer these questions, it is necessary to review the skeletal images to be sure the comparison is valid and understand how the T-scores were calculated. 


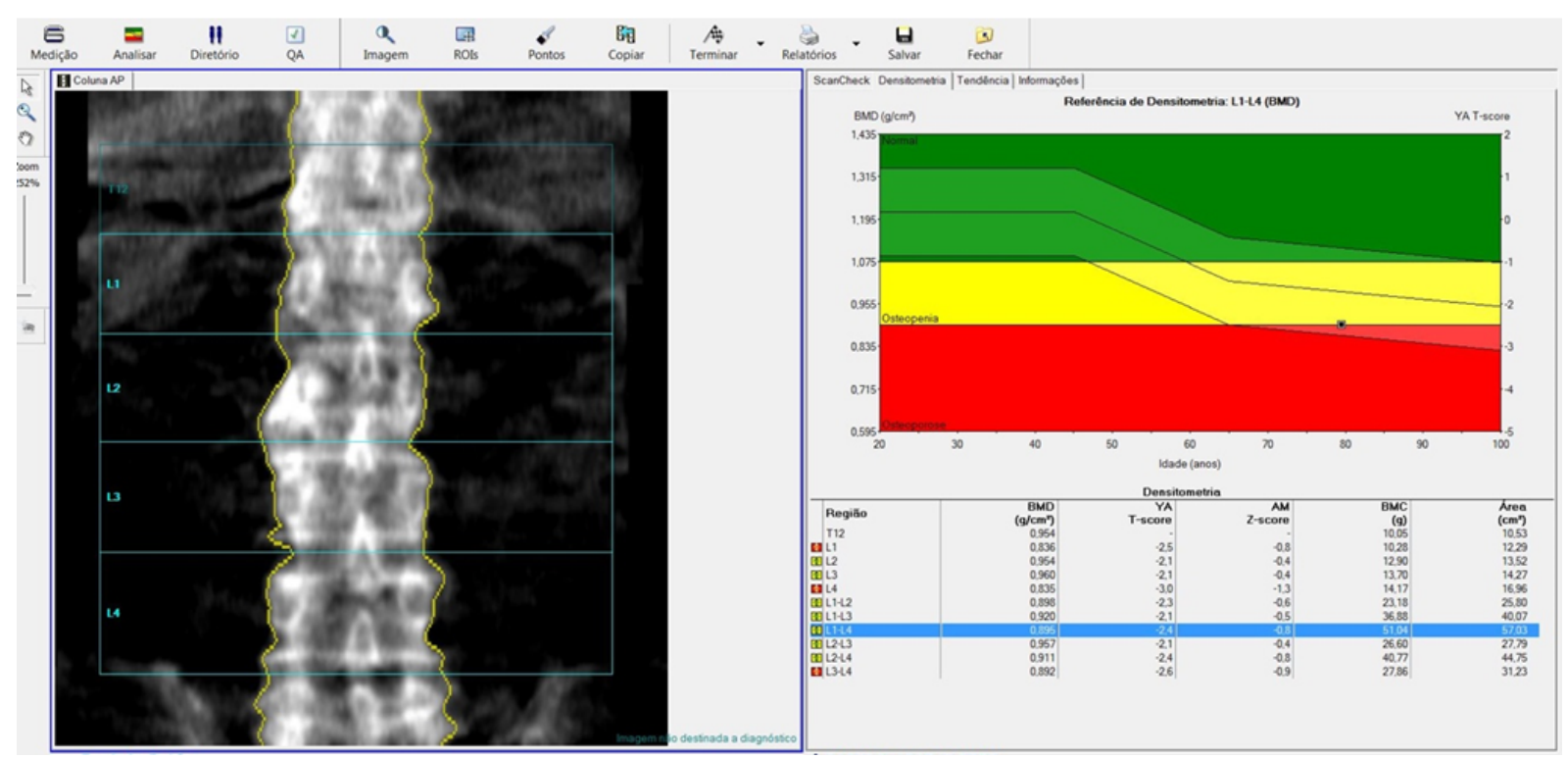

Figure 1: First DXA scan performed in 2014. This is a 79 years old male patient. The BMD at L1-L4 was $0.895 \mathrm{~g} / \mathrm{cm} 2$ and T-score was -2.4 (calculated with a female reference database).

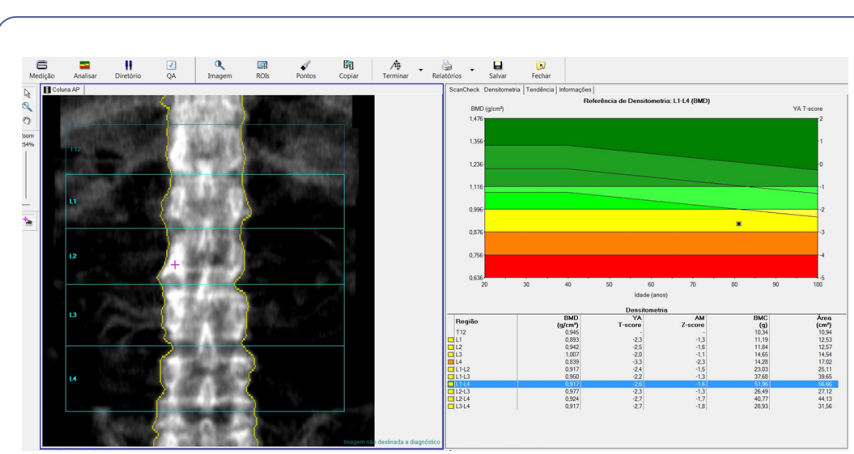

Figure 2: Second DXA scan performed in 2016. This a 81 year old male patient. The BMD at L1-L4 was $0.917 \mathrm{~g} / \mathrm{cm}^{2}$ and T-score was -2.6 (calculated with a male reference database). Note that the BMD is higher and the T-score is lower compared with the first DXA scan.

\section{Discussion}

Review of the spine images showed that they were comparable; however, a close look at the DXA printout revealed that different reference databases were used for Tscore calculations. This male patient had the first scan analysed with a female reference database and the second scan was analysed with a male reference database. For DXA interpreters and referring physicians, this illustrates the importance of reviewing both the images and information provided on the complete DXA printout, which identifies the reference database used. Changes in T-score due to unrecognized differences in reference databases may not represent actual changes in BMD and might lead to inappropriate clinical decisions. With this patient, when the baseline study was reanalysed using a male reference database for T-score calculation (Figure 3), comparison with the follow-up study showed a numerical improvement of both T-score and BMD, consistent with a beneficial effect of therapy. The patient was not a suboptimal responder to treatment.

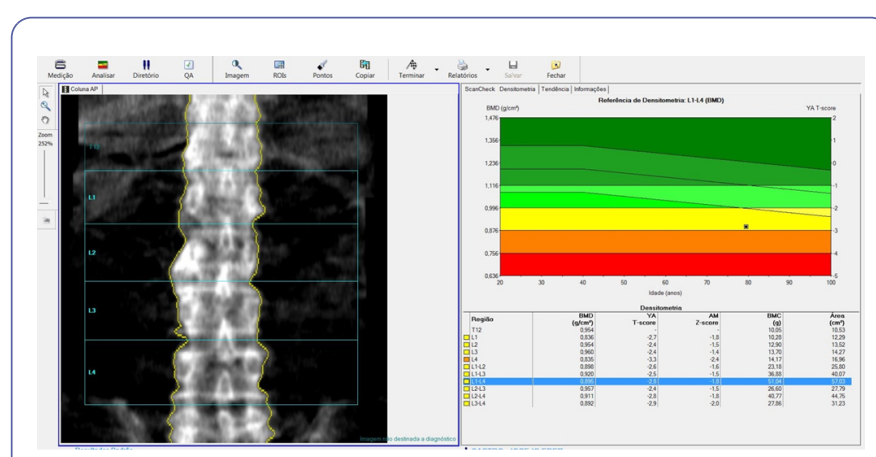

Figure 3: First DXA scan analysed again with the male database. Now the BMD at L1-L4 is $0.895 \mathrm{~g} / \mathrm{cm}^{2}$ (same as in the previous analysis) and T-score is -2.8 . When the second DXA scan is now compared with this scan, there is a numerical increase of both BMD and T-score.

There is controversy as to whether male or female reference databases should be used for T-score calculation in men. The ISCD recommends the use of a uniform Caucasian (non-race adjusted) female normative database for women and men of all ethnic groups (application of the recommendation may vary according to local requirements) [6]. The Endocrine Society guidelines for osteoporosis in men $[7,8]$, in contrast, state that a male reference database should be used for T-score calculation in men.

An analysis of the clinical implications of changing reference databases for T-scores in men8 found that by using female reference databases, the proportion of men classified as 
having normal bone mass increased from $22 \%$ to $33 \%$ and those identified as osteoporosis decreased from $29 \%$ to $17 \%$. If pharmacologic treatment were based on a T-score <-2.0, using female references databases would reduce the number of treated men for low bone mass from $46 \%$ to $32 \%$.

This case demonstrates the importance of using BMD (g/ $\mathrm{cm}^{2}$ ), not T-score, in performing serial comparisons of bone density. The ISCD recommends that BMD be used for quantitative serial DXA comparisons after precisions assessment has been conducted and the least significant change (LSC) calculated according to well-recognized international standards [9].

\section{Conclusion}

$B M D$, not T-score, should be used for assessing the skeletal response to treatment, in part because T-score values may change when different young-adult reference databases are used. Quantitative comparison of BMD requires knowledge of the LSC. The use of a female reference database for T-score calculation in men results in a higher T-score than when a male reference database is used and fewer men being classified as having low bone mass and osteoporosis. DXA technologists should take care to select the most appropriate reference database according to the facility's standard operating procedures. DXA interpreters should be vigilant in recognizing the database that is used and alert referring physicians when a change has been made.

\section{References:}

1. Center JR, Nguyen TV, Schneider D, Sambrook PN, Eisman J (1999) A Mortality after all major types of osteoporotic fracture in men and women: an observational study. Lancet 353: 878-882.

2. Seeman E (1995) The dilemma of osteoporosis in men. Am J Med 98.

3. Kanis JA, Oden A, Johnell O, De Laet C, Jonsson B, et al. (2003) The components of excess mortality after hip fracture. Bone 32 : 468-473.

4. Cooley H, Jones G (2001) International Original Article A Population-Based Study of Fracture Incidence in Southern Tasmania : Lifetime Fracture Risk and Evidence for Geographic Variations within the Same Country 12: 124-130.

5. Lewiecki EM, Borges JL (2006) Bone density testing in clinical practice. Arq Bras Endocrinol Metab 50: 586-595.

6. Shepherd JA, Schousboe JT, Broy SB, Engelke K, Leslie WD (2015) Executive Summary of the 2015 ISCD Position Development Conference on Advanced Measures From DXA and QCT: Fracture Prediction Beyond BMD. J Clin Densitom 18: 274-286.

7. Watts NB, Adler RA, Bilezikian JP (2012) Osteoporosis in men: an Endocrine Society clinical practice guideline. J Clin Endocrinol Metab 97: 1802-1822.

8. Wiemann LM, Vallarta-Ast N, Krueger D, Binkley N (2007) Effect of Female Database Use for T-score Derivation in Men. J Clin Densitom 10: 244-248.

9. Lewiecki EM, Binkley N, Morgan SL (2016) Best Practices for Dual-Energy X-ray Absorptiometry Measurement and Reporting: International Society for Clinical Densitometry Guidance. J Clin Densitom 1-14. 